\title{
Expansive cements for the manufacture of the concrete protective bandages
}

\author{
Yaroslav Yakymechko, Vladyslav Voloshynets \\ Warsaw University of Technology \\ Faculty of Civil Engineering, Mechanics and Petrochemistry \\ Lviv Polytechnic National University \\ Institute of Chemistry and Chemical Technologies \\ e-mail: Yaroslav.Yakymechko@pw.edu.pl, Vladyslav.Voloshynets@gmail.com
}

\begin{abstract}
One of the promising directions of the use of expansive cements is making the protective bandages for the maintenance of pipelines. Bandages expansive application of the compositions of the pipeline reinforce the damaged area and reduce stress due to compressive stress in the cylindrical area. Such requirements are best suited for expansive compositions obtained from portland cement and modified quicklime. The article presents the results of expansive cements based on quick lime in order to implement protective bandages pipelines.
\end{abstract}

Key words: expanding cement, quicklime, expansion effort, strength of bending and compressive

\section{Introduction}

Special cements are widely used in building. Such cements give new properties to products and constructions, especially during their exploitation in difficult conditions of the environment. Expansive cements belong to this group of cements. It should be noted that these cements do not meet existing European norms. For the receiving of the appropriate properties the composition and the amount of expansive additives in cement are important, as well as the technology of concretes production [1].

The receiving of the effect of cement stone expansion is obtained by the reaction of enttringite formation, when calcium aluminates interact with gypsum and portlandite, which is formed at hydration of silicate minerals of clinker, as well as at its adding in compositions with hydrate or quicklime. The authors [2] think that it is more reasonable to use the quicklime as a component of enttringite, not as independent expansive additive. 
The most effective is the application of expansive cements for small-grained concretes at high water-cement relations [3], as such concretes are characterized by increased contraction. One of the perspective directions of expansive small-grained concretes usage is making the protective bandages during the maintenance of pipelines of high pressure. For the maintenance the concrete mixture should have high mobility, and hardened concrete should have high density and low gas permeability [4].

Such requirements meet expansive compounds based on portlandcement and expansive additive based on modified quicklime [5,6]. Thus, the aim of this work was the development and investigation of the expansive cements with quicklime modified by saccharose, which are used for the maintenance of pipelines of high pressure.

\section{Materials and methods of investigation}

For the production of expansive compositions, the portland cement CEM I 42,5 R and ground quicklime SR EN 459 CL 90-Q have been used [7]. The lime has been modified by its grind with $1,0 \%$ mas. of saccharose and heating at $160{ }^{\circ} \mathrm{C}$. The chemical composition of cement according to the standard PN-EN 196-2 [8] and quicklime is given in a table 1.

Table 1: Chemical composition of the materials

\begin{tabular}{|l|c|c|c|c|c|c|c|c|c|c|c|}
\hline \multirow{3}{*}{ Binder } & \multicolumn{10}{|c|}{ Oxide, mas. \% } & $\begin{array}{c}\text { Loss of } \\
\text { ignition }\end{array}$ \\
\cline { 2 - 15 } & $\mathrm{CaO}$ & $\mathrm{SiO}_{2}$ & $\mathrm{Al}_{2} \mathrm{O}_{3}$ & $\mathrm{Fe}_{2} \mathrm{O}_{3}$ & $\mathrm{MgO}$ & $\mathrm{SO}_{3}$ & $\mathrm{Na}_{2} \mathrm{O}$ & $\mathrm{K}_{2} \mathrm{O}$ & $\mathrm{Cl}$ & $\mathrm{CO}_{2}$ & \\
\hline Cement & 64,5 & 21,3 & 4,94 & 2,30 & 2,18 & 3,01 & 0,13 & 0,86 & 0,07 & - & 3,06 \\
\hline Lime $^{*}$ & 92,8 & - & - & - & 0,7 & 0,4 & - & - & - & 2,2 & - \\
\hline
\end{tabular}

* data according to [7]

The normal consistence of the cement paste has been tested according to the norm PN-EN 196-3. The strength of the contraction of cement compositions at standard consistence has been determined on the 7th, 14th and 28th days, according to the norm PN-EN 196-1. The value of the tension during expansion has been determined in a special device according to the methods [9]. The content of portlandite, calcite and other products of aquation has been determined after 28 days of hardening using differencial thermal gravimetry. The microstructure and morphology of the crystal phase of the products of aquation of cement compositions have been analyzed using the electronic scanning microscopy.

\section{Result and discussion}

For the receiving of the strain compositions the portlandcent CEM I 42,5 R, the quicklime and saccharose additive have been used. The investigations of the influence of the structure of composition on the value of force of expansion have been carried out. The amount of water for the strain cement has been chosen on conditions of gaining the necessary mobility, determined by Suttard cylinder.

The investigations showed that at the increase of its amount the linear dependence between the content of $\mathrm{CaO}$ and the value of expansion occurs (Table 2). After 24 hours the 
compositions containing the quicklime more than 25,0 mas. $\%$ create the necessary force of expansion, the value of which stabilizes after 72 hours of hardening.

For the maintenance of the gas pipelines of high and medium pressure, the important indicator is the force of the pipeline suppression, which should have 3,0-5,0 $\mathrm{MPa}$, thus the content of the modified lime in the composition of the strain cement should have more than 30,0 mas. $\%$. It has been established that at adding more than 20,0 mas. $\%$ of the lime into the composition, the samples dilapidate in the process of hardening. But the investigation showed that during hardening in the limited volume, the strength of the stone increases, especially at distant terms of hardening (Table 3). The increase of the amount of $\mathrm{CaO}$ at early terms of hardening worsens physical and mechanical characteristics of strain compositions.

Table 2: The influence of the amount of lime with the additive 1,0 mas. $\%$ of saccharose on the force of expansion

\begin{tabular}{|c|c|c|c|c|c|c|}
\hline \multirow{2}{*}{ No } & \multicolumn{2}{|c|}{$\begin{array}{c}\text { Structure of composition, } \\
\text { mas. \% }\end{array}$} & \multirow{2}{*}{$\begin{array}{c}\text { Water/ } \\
\text { Solid }\end{array}$} & \multicolumn{3}{|c|}{$\begin{array}{c}\text { Force of expansion, MPa, } \\
\text { at the age, days }\end{array}$} \\
\cline { 2 - 4 } & Portland cement & Quicklime & & 1 & 3 & 7 \\
\hline 1 & 95 & 5 & 0,30 & 0 & 0,17 & 0,22 \\
\hline 2 & 90 & 10 & 0,32 & 0,12 & 0,32 & 0,45 \\
\hline 3 & 85 & 15 & 0,33 & 0,31 & 0,54 & 0,66 \\
\hline 4 & 80 & 20 & 0,35 & 0,55 & 0,75 & 0,97 \\
\hline 5 & 75 & 25 & 0,36 & 0,46 & 2,32 & 2,68 \\
\hline 6 & 70 & 30 & 0,38 & 0,98 & 4,63 & 4,89 \\
\hline
\end{tabular}

However, with the time of hardening the amount of crystal phase increases and the compression of the structure occurs, as a result of which the cement stone reaches the high values of durability on pressure. By the investigations of open porosity of strain cements with the adding of the quicklime and 1,0 mass. \% of saccharose it has been established that after 7 and 14 days porosity is $14,5-18,5 \%$ and $11,7-9,0 \%$ accordingly, and after 28 days it decreases to $7,0-8,5 \%$.

Table 3: Physical and mechanical characteristics of strain cements in terms of limited volume

\begin{tabular}{|c|c|c|c|c|c|c|}
\hline \multirow{2}{*}{ No } & \multicolumn{2}{|c|}{$\begin{array}{c}\text { Structure of composition, } \\
\text { mas. \% }\end{array}$} & \multirow{2}{*}{$\begin{array}{c}\text { Water } \\
\text { No }\end{array}$} & $\begin{array}{c}\text { Portland } \\
\text { cement }\end{array}$ & Quicklime & \multicolumn{3}{|c|}{$\begin{array}{c}\text { Force of bend /compression, MPa, } \\
\text { Solid the age, days }\end{array}$} \\
\cline { 2 - 3 } & 90 & 10 & 0,28 & $3,0 / 14,9$ & $4,8 / 19,6$ & $7,3 / 27,1$ \\
\hline 1 & 85 & 15 & 0,29 & $2,8 / 11,3$ & $5,9 / 18,5$ & $8,2 / 29,7$ \\
\hline 2 & 80 & 20 & 0,33 & $2,2 / 10,8$ & $6,3 / 15,2$ & $9,4 / 31,0$ \\
\hline 3 & 70 & 30 & 0,33 & $1,9 / 10,2$ & $7,1 / 14,7$ & $9,8 / 31,8$ \\
\hline 4 & & & & & & \\
\hline
\end{tabular}


Qualitative and quantitative amount of products of hydration of srtain cement has been determined by thermogravimertic and differential-thermal analysis (Table 4). The loss of mass at $145{ }^{\circ} \mathrm{C}$, which is accompanied by the appearance of clear endoeffects on the DTA curves, may be explained by secretion of physically and chemically bound water from hydrosilicates and enttringite. The loss of mass of the examples at $135-450{ }^{\circ} \mathrm{C}$ is caused by the decomposition of calcium hydrosilicates, enttringite and the beginning of the dehydration of hydroaluminates and monocarbonate of fourcalcium hydroaluminate.

The loss of mass at $450-550{ }^{\circ} \mathrm{C}$ is caused by the decomposition of portlandite, which was formed at the hydration of calcium oxide and $\mathrm{C}_{3} \mathrm{~S}$. At $520-725{ }^{\circ} \mathrm{C}$ the loss of mass of examples is explained by the processes of dehydration of hydroaluminates. At $720-1000{ }^{\circ} \mathrm{C}$ the loss of mass and the appearance of clear endoeffects on the DTA curves happens because of decomposition of $\mathrm{CaCO}_{3}$, formed by partial carbonation of portlandite.

Table 4: The results of thermogravimetric after 28 days of hardening of pastes in conditions of limited volume

\begin{tabular}{|c|c|c|c|c|c|c|c|}
\hline \multirow{3}{*}{$\begin{array}{c}\text { Composition } \\
\text { of binder }\end{array}$} & \multirow{2}{*}{\multicolumn{4}{|c|}{ Loss of mass at the temperature, ${ }^{\circ} \mathrm{C}$}} & \multirow{3}{*}{$\begin{array}{c}\text { General } \\
\text { losses, } \\
\%\end{array}$} & \multicolumn{2}{|c|}{ Content, $\%$} \\
\hline & & & & & & \multirow{2}{*}{ Portlandite } & \multirow{2}{*}{ Calcite } \\
\hline & $20-450$ & $450-550$ & $550-720$ & $720-1000$ & & & \\
\hline $\begin{array}{l}\text { Cement } 80 \% \\
\text { Lime } 20 \%\end{array}$ & 8,6 & 6,4 & 1,6 & 7,0 & 23,6 & 26,3 & 15,9 \\
\hline Cement $100 \%$ & 6,8 & 3,8 & 3,5 & 4,4 & 15,5 & 15,6 & 10,0 \\
\hline
\end{tabular}

Thus, at hardening of the strain composition in terms of limitation of the expansion, the amount of crystal phases in products of hydration increases, comparing with the portland cement without additives crystallization of which causes the system expansion.

According to the data of electronic microscopy the conditions of hardening change habitus of portlandite crystals and their dimentions (Fig.1). Therefore, the cement structure in normal conditions of hardening is characterized by the presence of big amount of micropores (Fig.1,a). In general, the neoplasms like spongy mass with the accumulation of fibrous crystals of high basic calcium hydrosilicates are viewed. The surface of cement examples in terms of limitation of expansion is solid small-grained structure (Fig.1,b), and close contact between particles of cement and lime contributes to the growth of portlandite crystals as hexagonal plates about $10-15 \mathrm{mkm}$. The small dispersed neoplasms of anomalous form prevail (Fig. 1c,d).

The strain cements are widely used for making small-grained concretes with low contraction. The perspective trend of small-grained concretes using is making protective bandages for maintenance of pipelines of high pressure on their base.

For receiving the small-grained concrete the strain compositions on the base of portlandcement and quicklime with the additive of 1,0 mas. \% saccharose have been used. It has been determined that the maximum effort of expansion $(6,6 \mathrm{MPa})$ and maximum filling of mixture is received when the amount of quartz sand is 40,0 mass. \% (Fig.2). 
During the exploitation the various defects on the surface of the pipe (cavities, insertions, scratches etc.), which diminish the bearing capability of the pipelines and can lead to formation of limiting states and destruction of the pipelines are formed.

In modern practice the methods of bandaging by rings and clutches are applied during the maintenance. The use of straing concrete allows maintaining without the breaking of structure exploitation, fully renewing the bearing capability of slackened defect zone of the pipeline. At this process the pressure, which appears between the pipes at hardening of concrete mixture, causes the effect of unloading of the main pipeline, displacing the tension on concrete and bandage.

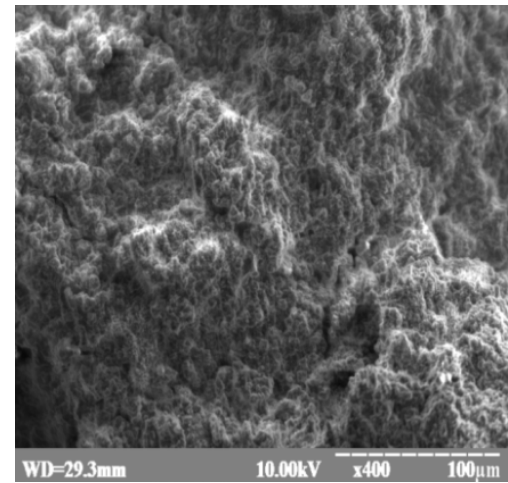

a

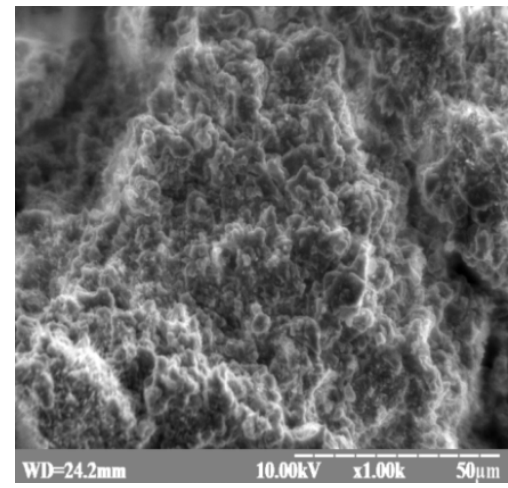

C

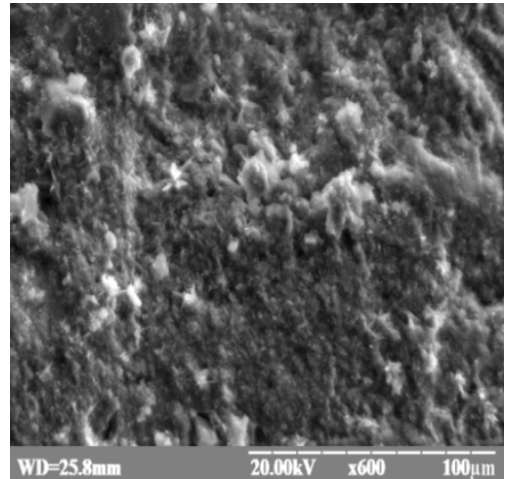

$\mathrm{b}$

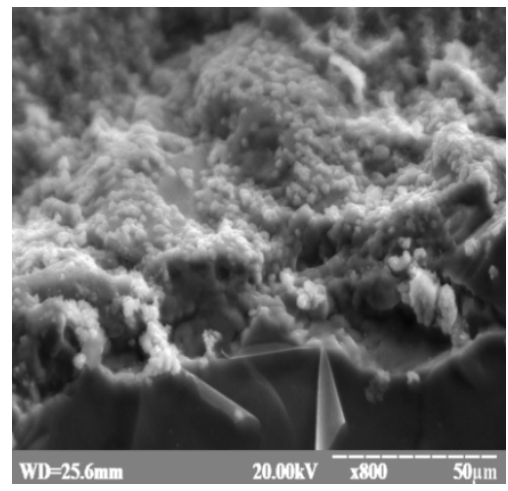

d

Figure 1: Microstructure of strain cement after 360 days of hardening: $a, b-$ in terms of free expansion; c,d- at limited volume 


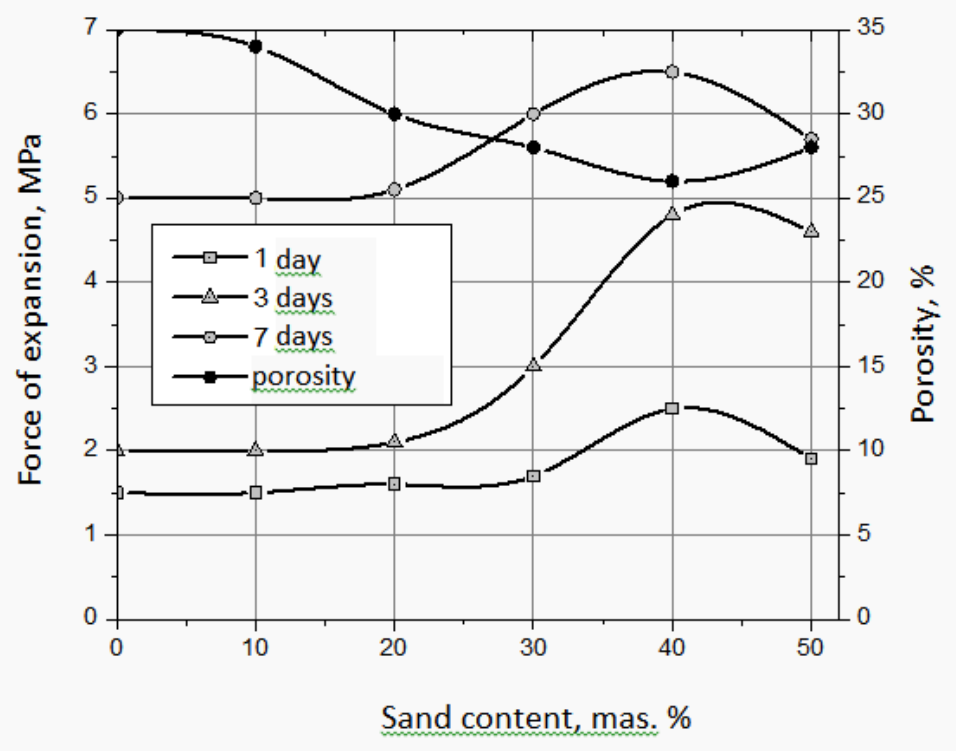

Figure 2: The influence of the amount of small filler on force of expansion and porosity of initial dry mixture

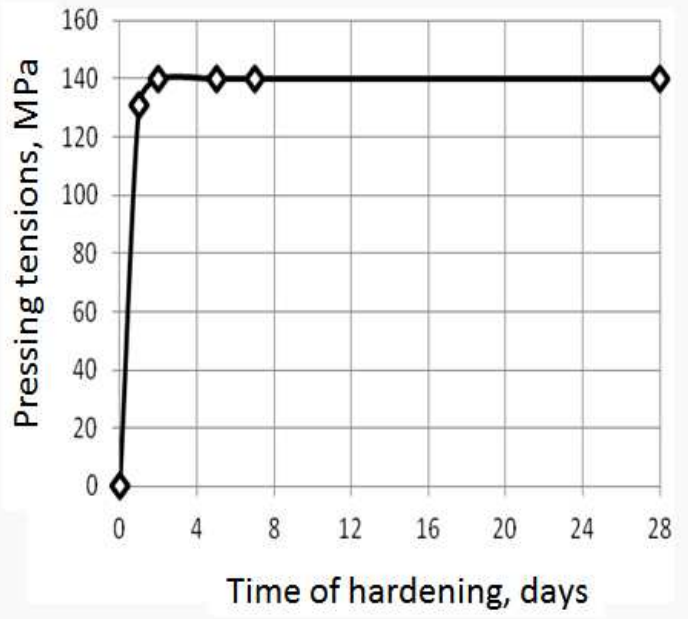

a

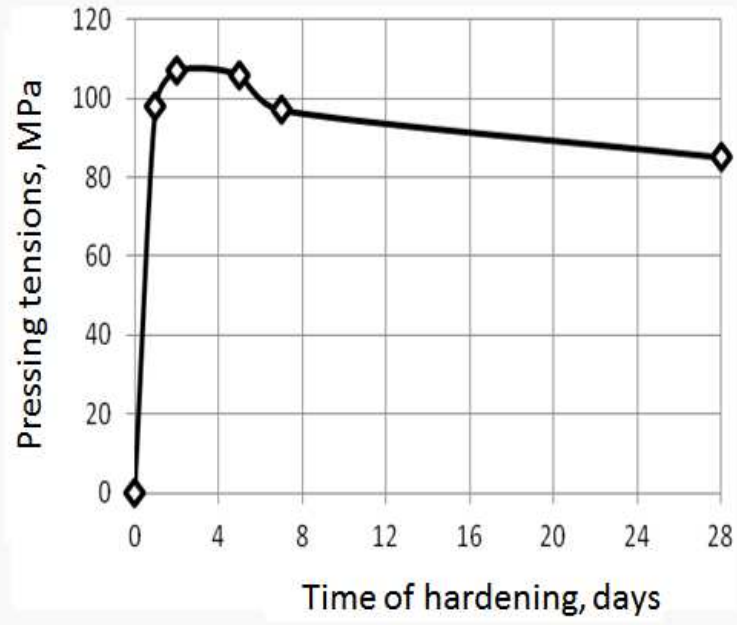

$\mathrm{b}$

Figure 3: The change of ring pressing tensions in a pipe (a) and stretching ones in a bandage (b)

For the control of the bandage deformation caused by the effect of expansion of concrete during hardening the indicative unfixed tensiometer (comparator) with a base $240 \mathrm{~mm}$ has been used. Ring and lengthwise deformations have been measured in the middle part at eight points. According to the results of the measurement the mean values of ring and lengthwise deformations have been calculated, and according to Guk's law for flat tense state the ring and lengthwise tensions have been found. After hardening of the cement solution, in the material of the casing the ring tensions of 3,6 $\mathrm{MPa}$, which have the pressure 3,6 $\mathrm{MPa}$ in the 
inter pipe space and diminishing of ring tensions in the wallside of strengthened zone of the gas pipeline from 211,4 MPa to 30,2 MPa, occurred.

The value of unloading tensions from the effect of expansion has been calculated according to the mathematical model of three-layered system of mechanics of a mis-shapen body, in which the pipeline and the casing are considered to be the thin walled covers, and the concrete layer works as a thick walled cylinder. The module of springiness and Poisson's ratio of the concrete layer $\left(E=1,42 \cdot 10^{4} \mathrm{MPa}, \mu=0,16\right)$ have been determined according to the results of testing of cylindrical samples, made from concrete mixture which has been used in the bandage, assembled on the gas pipeline.

The technology of bandage making is distinguished by its simplicity and can be applied both in the underground and overground sites. The most perspective it is for the maintenance of the pipelines located on the marshy areas and underwater crossings.

The tension of the expansive concrete has been carried out on the laboratory stand. According to the received data the model of the tense state of the pipeline has been calculated, using the software Kosmos. According to the results of tensions modeling and small-grained concrete transferring, it has been determined that pressure of the transported gas, which has an influence on the pipeline, is taken by the concrete and external bandage. It allows unloading of the pipeline and diminish the corrosive processes, which appear during the stretching tensions. Simultaneously, the transfer between concrete and metal of the pipeline and the bandage of the concrete is insignificant due to the friction.

It has been established (Fig. 3) that after 3 days the tension in the concrete is maximum, and the pressure $\mathrm{P}_{\mathrm{c}}=4,8 \mathrm{MPa}$ corresponds to the maximum value of ring squeezing effort in the pipeline, and the value of ring stretching tension in the bandage is $\mathrm{P}_{\mathrm{p}}=3,6 \mathrm{MPa}$.

\section{Conclusion}

Thus, the use of expansive astringent compositions causes the appearance of compression tension in the pipe and the extension in the bandage, meanwhile the formation of ring tensions ensures the transfer of a part of tension from the pipe to the bandage. In such conditions the significant compression of concrete, which is located in the intra pipe space, occurs, and in the main pipe the tension of the expansion, which influences the rate of metal corrosion, diminishes.

\section{References}

[1] Konik, Z., Małolepszy, J. , Roszczynialski, W., Stok, A. Production of expansive additive to portland cement. Jour. Eur. Ceram. Soc., 2007, no 27, p.605-609.

[2] Beaudoin, J.Calcium hydroxide in cement matrices: physic-mechanical and physic-chemical contributions. In: Konf. Workshop on Role of Calcium Hydroxide in Hydration and Deterioration of Concrete - Invited Contribution Island 2000: p.131-132.

[3] Trębaczkiewicz, P., M. Winch, M. Spoiwa na bazie cementu ekspansywnego. Górnictwo $i$ Geoinżynieria, 2007, no 31, p.411-426.

[4] Król, M. O naprawach i wzmocnienia konstrukcji budowlanych betonem ekspansywnym. Lublin, 2005. 
[5] Kurdowski, W. Chemia cementu i betonu.Wydawnictwo naukowe PWN, Warszawa, 2010.

[6] Якимечко , Я.Негашеная известь как компонент напрягающих цементов. Цемент и его применение, 1999, №4, с.31-33.

[7] http://www.lhoist.com/sites/lhoist/files/buk tradical_pl21k186.pdf

[8] EN-PN 196-1-3 Metody badania cementu.

[9] EN-PN 1015-3:2000. Metody badań zapraw do murów. 